\title{
Stage-discharge equation for simple flumes with semi-cylinder contractions
}

\author{
Ali R. Vatankhah ${ }^{1} \mathbb{D} \cdot$ M. Mohammadi ${ }^{1}$
}

Received: 5 December 2019 / Accepted: 21 February 2020 / Published online: 28 February 2020

(c) Springer Nature Switzerland AG 2020

\begin{abstract}
In this study, the outflow process of a simple flume with two semi-cylinders on either side of a rectangular channel having a zero slope was studied. This can be considered as one of the simplest form of contraction in a channel so it may have a broad applicability. From a practical viewpoint, the availability of a stage-discharge equation that can be reliably applied to a wide range of discharges would be of great practical importance. To extend the range of previous available data, new experimental runs were performed. Two new stage-discharge relationships were deduced: one general relationship by considering the contraction ratio and another relationship by neglecting the contraction ratio for a specified range of this variable. The proposed general stage-discharge relationship represents a novel equation to describe the flume outflow process. Other relationship can be used by neglecting the approaching channel width for the upstream Froude number ranges from 0.11 to 0.38 . Compared with the available stage-discharge relationships, the results indicate that the proposed simple relationships can be reliably used for a wide range of discharges with acceptable accuracy.
\end{abstract}

Keywords Simple flume Stage-discharge relationship · Wide application range · Experimental study · Dimensional analysis

\section{Introduction}

Open channels are commonly used for transportation of water for irrigation and water supply schemes. Measurement of the discharge in open channels and irrigation networks is one of the basic elements of water management. There are different approaches for measuring flow discharge in open channels. Contracting the cross section of the flow is one of the simplest and inexpensive methods for measuring flow discharge in open channels [1-8]. Among the hydraulic structures that used for flow measurement in open channels, flumes (without moving parts) are the most common in irrigation networks because of their simple geometry and ease of construction. Flumes have advantages over weirs, including: the ability to measure higher flow discharges, having less head loss, passing debris more easily and less maintenance requirements [9]. Flumes are constructed by a local contracting of the channel section. The flow depth at a location upstream of the flume throat can be converted to the flow discharge under free flow conditions.

Samani and Magallanez [10] using two half pipes on either side of a rectangular channel having a zero slope, constructed a simple and low-cost measurement flume that contracts the flow from a channel width of $B$ to a throat width of $B_{c}$. Figure 1 shows plan and longitudinal section of a horizontal rectangular channel with two half pipes located in its walls under free flow conditions. This flume has a horizontal floor with the same upstream and downstream widths. The flume accelerates the flow through the contraction of both the parallel sidewalls. Owing to its flat floor, the flume passes

Ali R. Vatankhah, arvatan@ut.ac.ir | ${ }^{1}$ Department of Irrigation and Reclamation Engineering, University College of Agriculture and Natural Resources, University of Tehran, P. O. Box 4111, Karaj 31587-77871, Iran. 


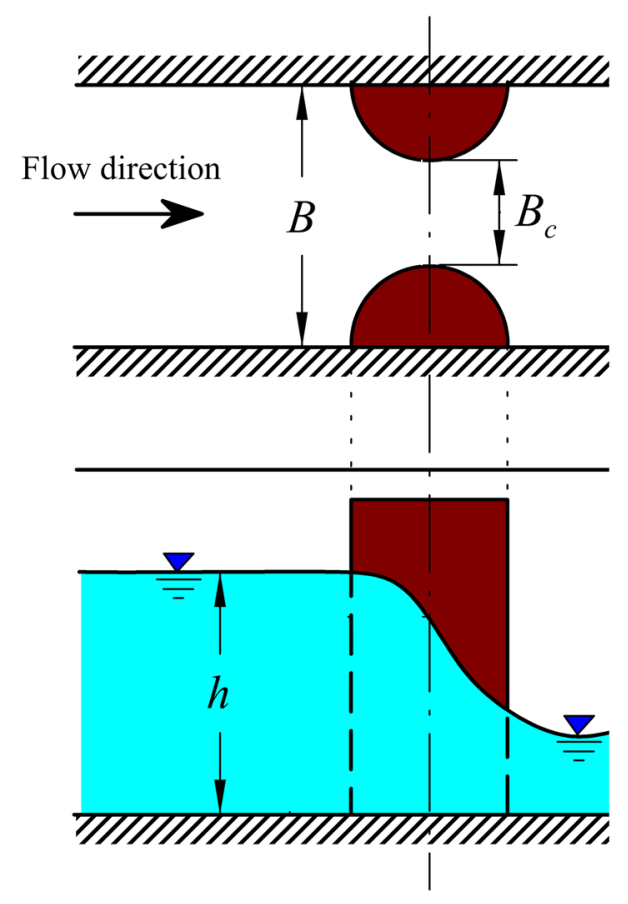

Fig. 1 Plan and longitudinal section of a horizontal rectangular channel with two half pipes located in its walls as a simple measurement flume

sediments and smaller debris easily. Deducing an accurate and general stage-discharge relationship for flumes with two half-pipe contractions is a key issue. Different stage-discharge relationships were proposed by different researchers for this flume under free flow conditions. However, further investigation needs to be done to clarify the effect of contraction ratio on a widely applicable stage-discharge equation. This study tackled this issue by using new experimental data, developing new stage-discharge equations and using sensitivity analysis.

\section{Literature review}

The stage-discharge equation for a flume contracted by two half pipes was investigated by different researches. Ferro [11] considered the flume discharge, $Q$, as a function of $B, B_{c^{\prime}}$ the upstream water depth, $h$, the water viscosity $\mu$ and acceleration due to gravity, $g$. The $\Pi$-theorem allows the organization of experimental parameters by dimensionless groups. According to the $\Pi$ -theorem of dimensional analysis, Ferro [11] deduced the following discharge relationship for free flow conditions:
$Q=a\left(\frac{h}{B_{c}}\right)^{b} \sqrt{g B_{c}^{5}}$

where $a$ and $b$ are regression coefficients that should be determined using experimental data. Equation (1) and the estimates of the coefficients $a=0.701$ and $b=1.59$ is firstly derived by Ferro [11] and recently is used by [12] to investigate the field application of three simple flumes constructed by contracting the flow cross section by installing cylinders for flow measurement in circular, rectangular, and trapezoidal channels.

Ferro [11] emphasized that the relationship between head and discharge in this type of flume is independent of contraction ratio $r=B_{c} / B$. Ferro [11] by using the 21 experimental data (digitized) of Samani and Magallanez [10], deduced Eq. (1) for $r=0.4,0.457$ and 0.597 and concluded that this stage-discharge equation is applicable for any contraction ratio value. Samani and Magallanez [10] emphasized that the stage-discharge equation may be independent of contraction ratio only for a narrow range of contraction ratio. Carollo et al. [6] and Vatankhah [13] showed that the contraction ratio is relevant. Carollo et al. [6] using the laboratory experimental runs carried out by Baiamonte and Ferro [14] showed that the discharge of the flume is a function of the contraction ratio $r=B_{c} / B$. They deduced the following stage-discharge relationship:

$Q=\frac{\left(B_{c}+\beta h\right) \sqrt{g h^{3}}}{\left(\frac{\alpha}{2}+\alpha \cos \left\{\frac{1}{3} \arccos \left[1-\frac{2 r^{2}\left(1+\beta h / B_{c}\right)^{2}}{\alpha^{3}}\right]\right\}\right)^{\frac{3}{2}}}$

For $a=1$ and $\beta=0$, Eq. (2) is a purely theoretical relation that can be obtained by applying the Bernoulli theorem between the upstream cross section and the throat cross section with critical flow depth. For $a>1$ and $\beta=0$, Eq. (2) is a semi-theoretical relation in which $\alpha$ is a coefficient, which takes into account both the Coriolis coefficient and the head losses occurring between the upstream section and the throat section. For $a=1$, head losses are neglected [6]. For low values of contraction ratio, Eq. (2) underestimates noticeably discharge for $\beta=0$ and this underestimate increases with increasing the flow discharge. In such cases, the channel contraction produces noticeable curvature of the streamlines approaching the narrow section which does not allow occurrence of a gradually varied flow condition. Baiamonte and Ferro [14] deduced Eq. (2) (for $a \neq 1$ and $\beta \neq 0$ ) applying the Bernoulli equation between the upstream section and the first section in downstream where the water surface profile is again gradually varied.

Using the experimental data (83 runs reported in Table 1) gathered by Baiamonte and Ferro [14] in a horizontal channel, Carollo et al. [6] derived $a=1.085$ and $\beta=0.243$. Equation (2) is highly dependent on the term 
Table 1 Experimental data from the literature and results collected for the rectangular flume in this study

\begin{tabular}{|c|c|c|c|c|c|c|c|c|c|c|c|c|c|c|}
\hline \multirow[t]{2}{*}{ Row } & \multicolumn{4}{|c|}{ This study $(B=0.25 \mathrm{~m})$} & \multicolumn{5}{|c|}{ Baiamonte and Ferro study [14] $(B=0.3 \mathrm{~m})$} & \multicolumn{5}{|c|}{ Baiamonte and Ferro study [14] $(B=0.3 \mathrm{~m})$} \\
\hline & $B_{c}(\mathrm{~m})$ & $r(-)$ & $h(\mathrm{~m})$ & $Q(\mathrm{l} / \mathrm{s})$ & Row & $B_{c}(\mathrm{~m})$ & $r(-)$ & $h(\mathrm{~m})$ & $Q(\mathrm{l} / \mathrm{s})$ & Row & $B_{c}(\mathrm{~m})$ & $r(-)$ & $h(\mathrm{~m})$ & $Q(1 / \mathrm{s})$ \\
\hline 1 & 0.075 & 0.3 & 0.1215 & 6.577 & 1 & 0.051 & 0.17 & 0.0609 & 1.552 & 42 & 0.144 & 0.48 & 0.0439 & 2.24 \\
\hline 2 & 0.075 & 0.3 & 0.1585 & 10.543 & 2 & 0.051 & 0.17 & 0.0741 & 2.093 & 43 & 0.144 & 0.48 & 0.0480 & 2.508 \\
\hline 3 & 0.075 & 0.3 & 0.1666 & 11.772 & 3 & 0.051 & 0.17 & 0.0811 & 2.508 & 44 & 0.144 & 0.48 & 0.0503 & 2.759 \\
\hline 4 & 0.075 & 0.3 & 0.2102 & 17.625 & 4 & 0.051 & 0.17 & 0.0881 & 2.872 & 45 & 0.144 & 0.48 & 0.0529 & 2.992 \\
\hline 5 & 0.075 & 0.3 & 0.2460 & 23.723 & 5 & 0.051 & 0.17 & 0.0935 & 3.202 & 46 & 0.144 & 0.48 & 0.0549 & 3.208 \\
\hline 6 & 0.075 & 0.3 & 0.2666 & 27.678 & 6 & 0.051 & 0.17 & 0.0966 & 3.402 & 47 & 0.144 & 0.48 & 0.0574 & 3.407 \\
\hline 7 & 0.075 & 0.3 & 0.2842 & 31.052 & 7 & 0.051 & 0.17 & 0.1008 & 3.732 & 48 & 0.144 & 0.48 & 0.0583 & 3.504 \\
\hline 8 & 0.100 & 0.4 & 0.0498 & 1.773 & 8 & 0.051 & 0.17 & 0.1056 & 3.954 & 49 & 0.144 & 0.48 & 0.0625 & 3.908 \\
\hline 9 & 0.100 & 0.4 & 0.0751 & 3.569 & 9 & 0.051 & 0.17 & 0.1099 & 4.244 & 50 & 0.144 & 0.48 & 0.0647 & 4.159 \\
\hline 10 & 0.100 & 0.4 & 0.1030 & 6.194 & 10 & 0.051 & 0.17 & 0.1144 & 4.613 & 51 & 0.144 & 0.48 & 0.0684 & 4.551 \\
\hline 11 & 0.100 & 0.4 & 0.1344 & 10.015 & 11 & 0.051 & 0.17 & 0.1159 & 4.722 & 52 & 0.144 & 0.48 & 0.0686 & 4.58 \\
\hline 12 & 0.100 & 0.4 & 0.1674 & 15.061 & 12 & 0.051 & 0.17 & 0.1178 & 4.864 & 53 & 0.144 & 0.48 & 0.0704 & 4.733 \\
\hline 13 & 0.100 & 0.4 & 0.1980 & 21.030 & 13 & 0.051 & 0.17 & 0.1205 & 5.012 & 54 & 0.144 & 0.48 & 0.0723 & 4.87 \\
\hline 14 & 0.100 & 0.4 & 0.2236 & 25.821 & 14 & 0.051 & 0.17 & 0.1227 & 5.245 & 55 & 0.144 & 0.48 & 0.0739 & 4.978 \\
\hline 15 & 0.100 & 0.4 & 0.2500 & 31.631 & 15 & 0.078 & 0.26 & 0.0500 & 1.552 & 56 & 0.144 & 0.48 & 0.0750 & 5.274 \\
\hline 16 & 0.100 & 0.4 & 0.2747 & 37.176 & 16 & 0.078 & 0.26 & 0.0601 & 2.087 & 57 & 0.180 & 0.6 & 0.0307 & 1.558 \\
\hline 17 & 0.150 & 0.6 & 0.0324 & 1.444 & 17 & 0.078 & 0.26 & 0.0695 & 2.633 & 58 & 0.180 & 0.6 & 0.0378 & 2.161 \\
\hline 18 & 0.150 & 0.6 & 0.0448 & 2.466 & 18 & 0.078 & 0.26 & 0.0746 & 2.981 & 59 & 0.180 & 0.6 & 0.0421 & 2.633 \\
\hline 19 & 0.150 & 0.6 & 0.0697 & 5.077 & 19 & 0.078 & 0.26 & 0.0786 & 3.294 & 60 & 0.180 & 0.6 & 0.0457 & 3.043 \\
\hline 20 & 0.150 & 0.6 & 0.0916 & 8.200 & 20 & 0.078 & 0.26 & 0.0828 & 3.498 & 61 & 0.180 & 0.6 & 0.0491 & 3.362 \\
\hline 21 & 0.150 & 0.6 & 0.1101 & 11.443 & 21 & 0.078 & 0.26 & 0.0866 & 3.766 & 62 & 0.180 & 0.6 & 0.0512 & 3.589 \\
\hline 22 & 0.150 & 0.6 & 0.1301 & 15.181 & 22 & 0.078 & 0.26 & 0.0885 & 3.948 & 63 & 0.180 & 0.6 & 0.0521 & 3.777 \\
\hline 23 & 0.150 & 0.6 & 0.1554 & 21.490 & 23 & 0.078 & 0.26 & 0.0917 & 4.198 & 64 & 0.180 & 0.6 & 0.0552 & 4.033 \\
\hline 24 & 0.150 & 0.6 & 0.1810 & 27.356 & 24 & 0.078 & 0.26 & 0.0951 & 4.431 & 65 & 0.180 & 0.6 & 0.0557 & 4.238 \\
\hline 25 & 0.150 & 0.6 & 0.2046 & 34.072 & 25 & 0.078 & 0.26 & 0.0974 & 4.653 & 66 & 0.180 & 0.6 & 0.0571 & 4.431 \\
\hline 26 & 0.150 & 0.6 & 0.2270 & 39.836 & 26 & 0.078 & 0.26 & 0.0996 & 4.801 & 67 & 0.180 & 0.6 & 0.0583 & 4.58 \\
\hline 27 & 0.150 & 0.6 & 0.2626 & 50.381 & 27 & 0.099 & 0.33 & 0.0444 & 1.558 & 68 & 0.180 & 0.6 & 0.0597 & 4.733 \\
\hline 28 & 0.221 & 0.88 & 0.0639 & 6.749 & 28 & 0.099 & 0.33 & 0.0540 & 2.24 & 69 & 0.180 & 0.6 & 0.0621 & 4.938 \\
\hline 29 & 0.221 & 0.88 & 0.0774 & 9.534 & 29 & 0.099 & 0.33 & 0.0595 & 2.577 & 70 & 0.243 & 0.81 & 0.0240 & 1.572 \\
\hline 30 & 0.221 & 0.88 & 0.0918 & 13.413 & 30 & 0.099 & 0.33 & 0.0654 & 3.043 & 71 & 0.243 & 0.81 & 0.0294 & 2.096 \\
\hline 31 & 0.221 & 0.88 & 0.1041 & 16.251 & 31 & 0.099 & 0.33 & 0.0695 & 3.311 & 72 & 0.243 & 0.81 & 0.0318 & 2.52 \\
\hline 32 & 0.221 & 0.88 & 0.1203 & 21.300 & 32 & 0.099 & 0.33 & 0.0714 & 3.601 & 73 & 0.243 & 0.81 & 0.0352 & 2.889 \\
\hline 33 & 0.221 & 0.88 & 0.1371 & 26.339 & 33 & 0.099 & 0.33 & 0.0749 & 3.777 & 74 & 0.243 & 0.81 & 0.0369 & 3.214 \\
\hline 34 & 0.221 & 0.88 & 0.1571 & 31.906 & 34 & 0.099 & 0.33 & 0.0780 & 4.033 & 75 & 0.243 & 0.81 & 0.0379 & 3.412 \\
\hline 35 & 0.221 & 0.88 & 0.1807 & 40.033 & 35 & 0.099 & 0.33 & 0.0799 & 4.198 & 76 & 0.243 & 0.81 & 0.0399 & 3.639 \\
\hline \multirow[t]{7}{*}{36} & 0.221 & 0.88 & 0.2559 & 67.886 & 36 & 0.099 & 0.33 & 0.0825 & 4.437 & 77 & 0.243 & 0.81 & 0.0413 & 3.866 \\
\hline & & & & & 37 & 0.099 & 0.33 & 0.0844 & 4.659 & 78 & 0.243 & 0.81 & 0.0436 & 4.12 \\
\hline & & & & & 38 & 0.099 & 0.33 & 0.0866 & 4.801 & 79 & 0.243 & 0.81 & 0.0436 & 4.276 \\
\hline & & & & & 39 & 0.099 & 0.33 & 0.0888 & 4.944 & 80 & 0.243 & 0.81 & 0.0457 & 4.587 \\
\hline & & & & & 40 & 0.144 & 0.48 & 0.0353 & 1.558 & 81 & 0.243 & 0.81 & 0.0470 & 4.729 \\
\hline & & & & & 41 & 0.144 & 0.48 & 0.0405 & 2.008 & 82 & 0.243 & 0.81 & 0.0477 & 4.871 \\
\hline & & & & & & & & & & 83 & 0.243 & 0.81 & 0.0487 & 5.012 \\
\hline
\end{tabular}

$B_{c}+\beta h$ whose mathematical form cannot be determined theoretically. Hence, any formulation like Eq. (2) with $\beta \neq 0$ is not a purely theoretical relation.

Vatankhah [13] also proposed the following discharge $Q=\frac{a B_{c} \sqrt{g h^{3}\left[1+b\left(h / B_{c}\right)^{c}\right]^{3}}}{\left\{\frac{1}{2}+\cos \left[\frac{1}{3} \arccos \left(1-2 r^{2}\right)\right]\right\}^{\frac{3}{2}}}$ relationship for free outflow conditions: 
in which $a, b$ and $c$ are empirical coefficients that should be determined using experimental data. Using the experimental runs ( 83 runs) carried out by Baiamonte and Ferro [14] in a (smooth) rectangular flume of width $B=0.3 \mathrm{~m}$ $(1.6 \leq Q \leq 5.3 \mathrm{l} / \mathrm{s}$ and $0.17 \leq r \leq 0.81)$, Vatankhah [13] derived $a=0.826, b=0.214$ and $c=0.76$. Equation (3) is also not a purely theoretical relation.

Samani and Magallanez [10] performed laboratory experiments ( 21 runs with discharges up to $27.5 \mathrm{l} / \mathrm{s}$ ) for the narrow range of contraction ratio values $0.4 \leq r \leq 0.593$, and performed field experiments ( 5 runs) up to $380 \mathrm{l} / \mathrm{s}$ for $r=0.4\left[\left(B-B_{c}\right) / B_{c}=1-r=0.6\right]$. They installed a gauge on the upstream side of the cylinder to measure the water depth, $h$, upstream of the contraction section. But, there will be water surface fluctuation on the cylinder wall (at the gauge station). The gauge station should be installed at the upstream of the device and far enough to eliminate the water surface fluctuations around the contraction section. Due to the different conditions of the gauge station used for measuring the upstream water depth, $h$, the condition of the experimental data gathered by Samani and Magallanez [10] is different from this study and Baiamonte and Ferro [14]. For such cases (different measurement conditions), the proposed stage-discharge formulas should be recalibrated. Di Stefano et al. [15] performed field experiments up to $17 \mathrm{l} / \mathrm{s}$ for the wide range of contraction ratio values $0.17 \leq r \leq 0.81$ and $B=0.3 \mathrm{~m}$. These results are available in the regression functional form of $Q=a^{1.5}\left(g B_{c}^{5}\right)^{0.5}\left(h / B_{c}\right)^{1.5 n}(a$ and $n$ were given for a specified $r$ ). The original data are not available for the experiments performed by Di Stefano et al. [15].

Recalibrating Eq. (1) for the experimental runs (83 runs) carried out by Baiamonte and Ferro [14] yields:

$Q=0.612\left(\frac{h}{B_{c}}\right)^{1.585} \sqrt{g B_{c}^{5}}$

The values of the regression coefficients, were obtained using Excel solver provided with Microsoft Excel by using a powerful search method named generalized reduced gradient (GRG) and by minimizing the summation of the absolute relative errors $\left(=\left|Q_{\mathrm{m}}-Q_{\text {cal }}\right| / Q_{\mathrm{m}} \times 100\right.$ in which $Q_{\mathrm{m}}$ and $Q_{\text {cal }}$ are measured and calculated discharges respectively).

In this research, a new stage-discharge equation for flumes with two half-pipe contractions was deduced and calibrated using the experimental runs (83 runs, $0.17 \leq r \leq 0.81$ and $1.6 \leq Q \leq 5.3 \mathrm{l} / \mathrm{s}$ ) carried out by Baiamonte and Ferro [14]. Then, this equation was validated by new laboratory measurements carried out in this study (36 runs, $0.3 \leq r \leq 0.88$ and $1.44 \leq Q \leq 67.9 \mathrm{l} / \mathrm{s}$ ) for different values of the contraction ratio, $r$. In this study, the water depth, $h$, was measured at a distance of $0.6 \mathrm{~m}$ upstream of the contraction section. Baiamonte and
Ferro [14] measured the water depth in the cross section having a distance equal to $B_{c}$ from the contraction section $\left(5.1 \leq B_{c} \leq 24.2 \mathrm{~cm}\right)$. It seems that the upstream depth, $h$, is almost constant with the minimum variation when the measuring location was farther than about $B_{c}$ and thus two experimental setups are comparable. In comparison with Eqs. (2)-(4), the new deduced stage-discharge equation in this study has the advantage of being simple, accurate and general. Moreover, a new stage-discharge equation was deduced by neglecting the approaching channel width $B$ for a specified range of the contraction ratio, $r$.

\section{New stage-discharge relationship}

In practice, the flow depth in flume is greater than $4 \mathrm{~cm}$, thus the surface tension effects can be neglected. Different stage-discharge models can be constructed based on intuition and experience. Under free flow conditions, the flume discharge, $Q$, can be considered as a function of several variables including $B, B_{c^{\prime}} h, g, \mu$ and the water density $\rho\left[Q=f\left(B, B_{c^{\prime}} h, g, \mu, \rho\right)\right.$ where $f$ symbolizes a function]. The $\Pi$-theorem allows the organization of experimental runs by dimensionless groups. Using $B_{c^{\prime}} g$, and $\rho$ as repeating independent variables, the following dimensionless groups was obtained ("Appendix 1"):

$\Pi_{1}=\frac{Q}{\sqrt{g B_{c}^{5}}}$

$\Pi_{2}=\frac{h}{B_{c}}$

$\Pi_{3}=r=\frac{B_{c}}{B}$

$\Pi_{4}=\frac{\mu}{\rho \sqrt{g B_{c}^{3}}}$

The dimensionless groups can be combined to obtain new dimensionless groups. Using Eqs. (6) and (8), the Reynolds number, $\mathrm{R}$, can be defined as $\mathrm{R}=\Pi_{2}^{0.5} / \Pi_{4}=\rho(g h)^{0.5} \mathrm{~B}_{\mathrm{c}} / \mu$. The effects of the Reynolds number, $R$, has been found to be negligible $[6,10,11,14,15]$. Neglecting the effect of the Reynolds number, the functional relationship of the flume can be rewritten as the following form [14]:

$\frac{Q}{\sqrt{g B_{c}^{5}}}=F_{1}\left(r, \frac{h}{B_{c}}\right)$ 
in which $F_{1}$ is a functional symbol. The functional relation, $F_{1}$, among the independent dimensionless parameters must be determined experimentally [16].

The dimensionless groups can be combined to obtain new dimensionless groups. By combining the original dimensionless groups [Eqs. (5)-(7)], the functional relationship of the flume can be written as:

$\frac{Q}{B_{c} \sqrt{g h^{3}}}=F_{2}\left(r, \frac{h}{B_{c}}\right)$

in which $F_{2}$ is a functional symbol.

The left hand side of Eq. (10) was obtained by $\Pi_{1} / \Pi_{2}^{3 / 2}$. This dimensionless form can also be deduced by theoretical discharge equation of the rectangular weirs.

Different mathematical models can be considered based on the dimensionless groups obtained by the Buckingham's theorem of dimensional analysis. The following power form is first considered for the stage-discharge relation of the flume:

$\frac{Q}{B_{c} \sqrt{g h^{3}}}=a r^{b}\left(\frac{h}{B_{c}}\right)^{c}$

The values of the regression coefficients in Eq. (11) were obtained using the experimental runs ( 83 runs) carried out by Baiamonte and Ferro [14] and by minimizing the summation of the absolute relative errors of the estimated discharges as $a=0.65, b=0.05$ and $c=0.11$. Equation 11 has an average error (mean absolute percentage error) of $4.9 \%$. As depicted in Fig. 2, 65\% of the errors are within $\pm 5 \%$. According to this figure, the error distribution is not normal. Figure 3 shows the experimental pairs $\left[Q / B_{c}\left(g h^{3}\right)^{0.5}, r^{0.05}\left(h / B_{c}\right)^{0.11}\right]$. As noted, the data

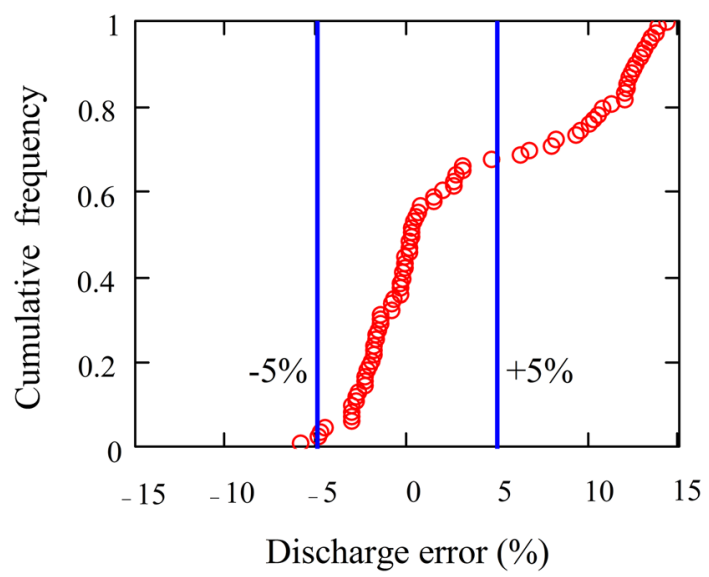

Fig. 2 Cumulative frequency distribution of the errors for the discharge values calculated by Eq. (11) with $a=0.65, b=0.05$ and $c=0.11$ ( 83 runs)

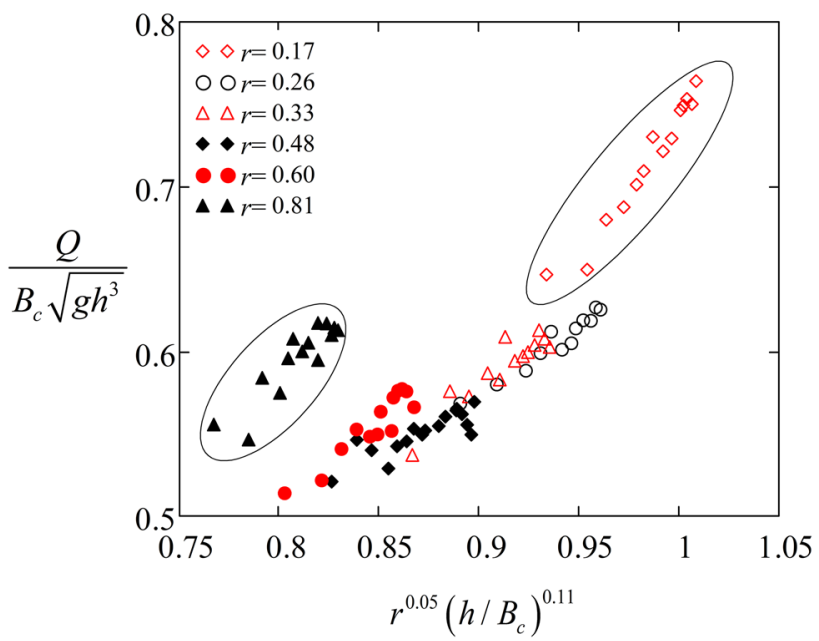

Fig. 3 Graphical representation of experimental pairs shows that there is not a unique relation between $Q / B_{c}\left(g h^{3}\right)^{0.5}$ and $r^{0.05}\left(h / B_{c}\right)^{0.11}$

points of $r=0.17$ and 0.81 do not collapse near a single curve along with other data points. The figure indicates that $Q / B_{c}\left(g h^{3}\right)^{0.5}$ cannot be accurately expressed only by a single dimensionless variable in the form of $r^{b}\left(h / B_{c}\right)^{c}$ and there is not a functional relation between two variables $Q / B_{c}\left(g h^{3}\right)^{0.5}$ and $r^{b}\left(h / B_{c}\right)^{c}$. According to Fig. 3, for the wide range of $0.17 \leq r \leq 0.81$, the dimensionless discharge is the function of both $r$ and $r^{b}\left(h / B_{c}\right)^{c}$. A comparison between measured discharges $Q / B_{c}\left(g h^{3}\right)^{0.5}$ and those calculated by Eq. (11) (with $a=0.65, b=0.05$ and $c=0.11$ ) is also shown in Fig. 4. As noted, Eq. (11) is not able to collapse all data points on the perfect line (deviations are apparent for the

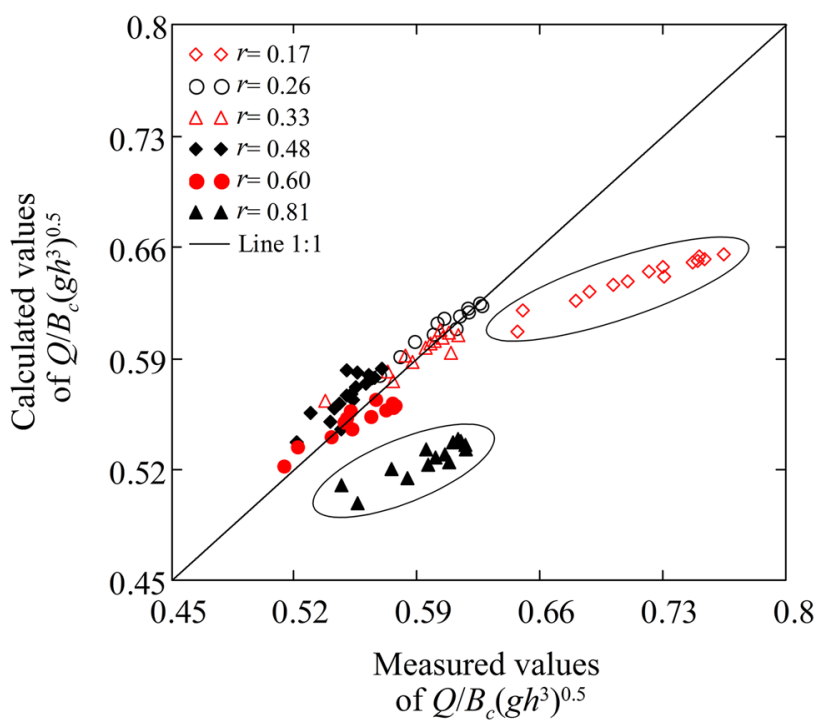

Fig. 4 Comparison between measured discharges $Q / B_{c}\left(g h^{3}\right)^{0.5}$ and those calculated by Eq. (11) with $a=0.65, b=0.05$ and $c=0.11$ (83 runs) 
data points of $r=0.17$ and 0.81 ). According to the figure, only for the range of $0.26 \leq r \leq 0.6$, the dimensionless discharge may be considered as a function of only $r^{b}\left(h / B_{c}\right)^{c}$.

The Buckingham's theorem of dimensional analysis only provides the dimensionless groups describing the phenomenon, and does not provide the specific relationship among the dimensionless groups $[16,17]$. Using these dimensionless groups, different discharge models can be constructed based on the background, intuition, experience, as well as theoretical considerations. As mentioned, the dimensionless discharge is the function of both $r$ and $r^{b}\left(h / B_{c}\right)^{c}$. By adding the linear term $d r$ to right hand side of Eq. (11), this study proposes the following nonlinear form for the stage-discharge relation of the flume:

$\frac{Q}{B_{c} \sqrt{g h^{3}}}=a r^{b}\left(\frac{h}{B_{c}}\right)^{c}+d r$

The applicability of this model should be verified and tested by experimental data. The values of the regression coefficients in Eq. (12) were obtained (using 83 runs) as $a=0.407, b=-0.16, c=0.263$ and $d=0.407$. Equation 12 has an average error of $1.66 \%$. As depicted in Fig. 5, the error distribution is normal and $99 \%$ of the errors are within $\pm 5 \%$. All models presented by Eqs. (2), (3), (4) and (12) have been calibrated using the experimental data (83 runs) of Baiamonte and Ferro [14] which are limited to discharges $1.6 \leq Q \leq 5.3 \mathrm{l} / \mathrm{s}$. The validation of the proposed models needs new experimental data.

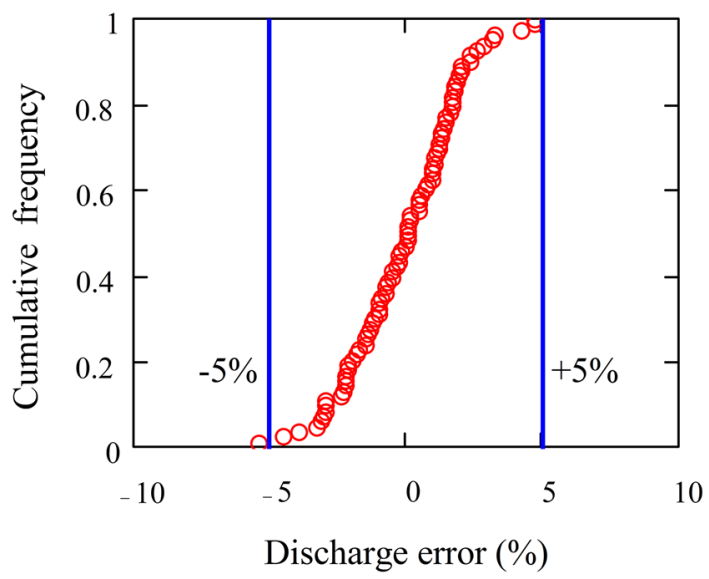

Fig. 5 Cumulative frequency distribution of the errors for the discharge values calculated by Eq. (12) with $a=0.407, b=-0.16$, $c=0.263$ and $d=0.407$ ( 83 runs)

\section{New experimental data}

To extend the range of previous data, new experimental runs were performed using the flow discharges ranging from 1.44 to $67.9 \mathrm{l} / \mathrm{s}$. The experiments were performed at the hydraulic laboratory of the Irrigation and Reclamation Engineering Department, University of Tehran, Karaj, Iran. The experimental setup was a rectangular Plexiglas flume of width $0.25 \mathrm{~m}$, depth $0.5 \mathrm{~m}$ and length $12 \mathrm{~m}$. The flow was measured using the triangular (low discharges) and rectangular (high discharges) weirs. The weirs installed and fixed on the experimental setup, then were calibrated using an electromagnetic flow meter with an accuracy of $\pm 0.5 \%$. The measurements were carried out for four different cylinder radiuses $(1.45,5,7.5$ and $8.75 \mathrm{~cm}$ ). Upstream water depths were measured at the upstream of the rectangular flume using a point gauge with an accuracy of $0.1 \mathrm{~mm}$. Water depth was measured at a distance of $0.6 \mathrm{~m}$ upstream of the contraction section. The gauge station of upstream water depth, $h$, should be far enough to eliminate the water surface effects around the contraction section. A total number of 36 runs were performed for free flow condition. For each experiment run, the flow discharges, $Q$, and the upstream water depth, $h$, were measured. The upstream water depth, $h$, was ranging from 3.2 to $28.4 \mathrm{~cm}$. The Reynolds number, $R$, was ranging from $0.4 \times 10^{8}$ to $3.5 \times 10^{8}$ which indicates that the effect of viscosity is negligible. Figure 6 shows one of the tested flumes in this research. The data of Baiamonte and Ferro [14] and the measurements carried out in this investigation for different values of $r$, are presented in Table 1. While the upstream Froude number of the study conducted by Baiamonte and Ferro [14] is ranging from 0.11 to 0.50 , the upstream Froude number of this study ranges from 0.20 to 0.67 (a higher upper limit which is important in practice). A comparison between the experimental data ranges of this study and Baiamonte and Ferro [14] is shown in Fig. 7. As seen, the data of this study extend the range of the experiments by Baiamonte and Ferro [14]. As shown in Fig. 7, Eq. (12) is in good agreement with both experimental data sets.

\section{Validation of proposed models}

The average and maximum relative errors of the proposed models are computed and reported in Table 2 . All models are calibrated only by the data of Baiamonte and Ferro [14]. The assumptions made in deriving the discharge equation are that the rectangular channel is 
Fig. 6 View of one of the tested flumes in this study
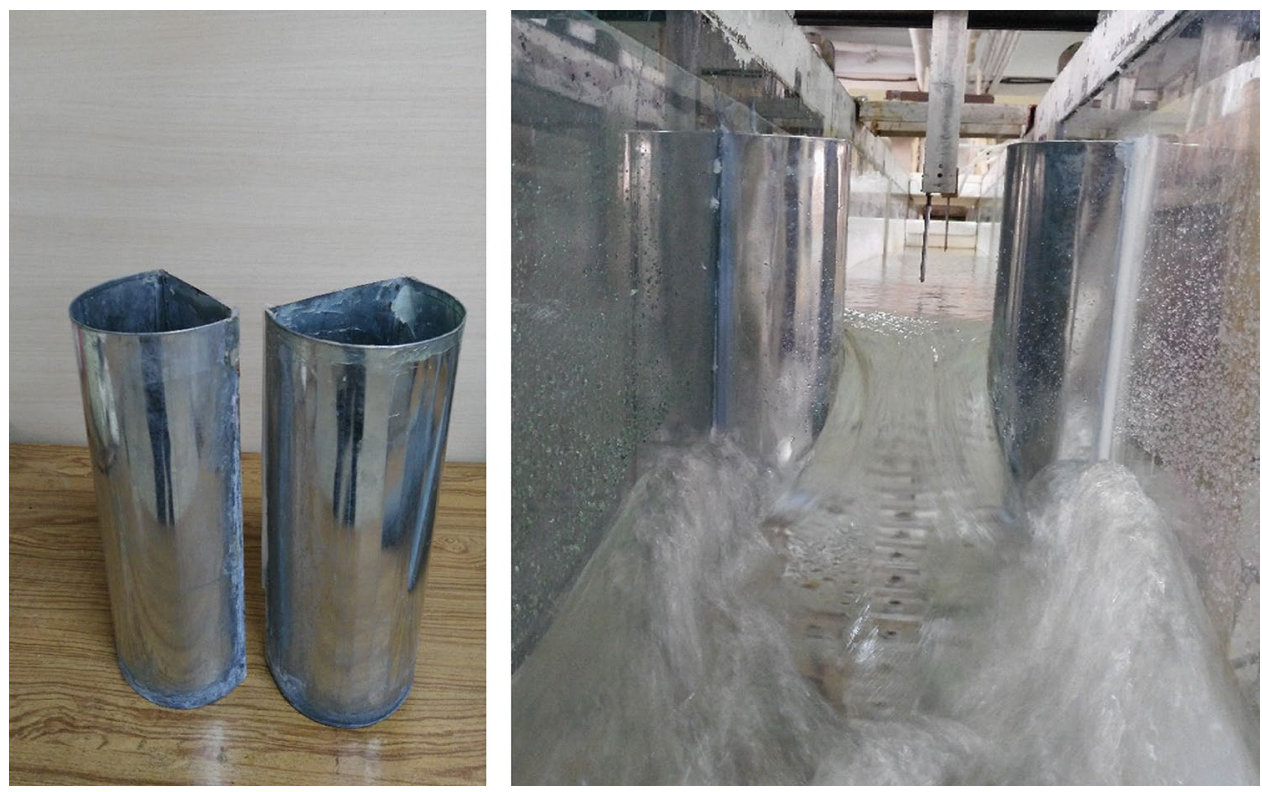
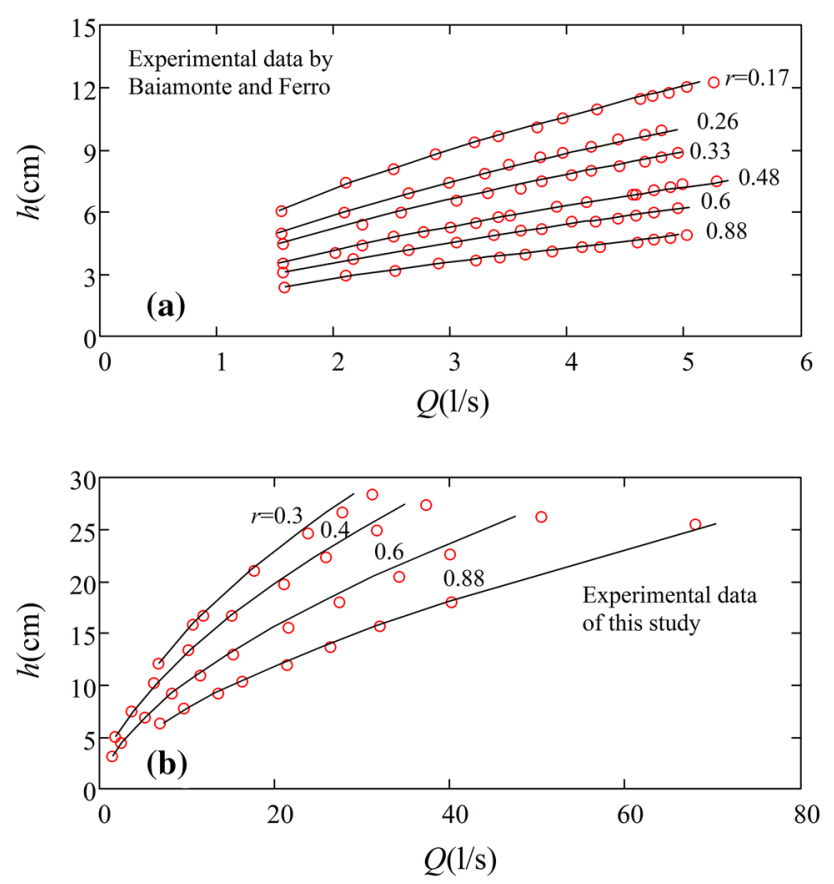

Fig. 7 Comparison between the experimental data ranges a Baiamonte and Ferro, $\mathbf{b}$ this study (hollow circles: experimental data and solid lines: proposed stage-discharge Eq. 12)

horizontal, the flow is free, and viscous and surface tension effects are negligible. Cumulative frequency distribution of the errors for the discharge values calculated by different models is depicted in Fig. 8 for all data sets (119 runs). The frequency distributions of the errors for all models are normal (have no bias) except for Model
III. Models I, II and IV are valid for $1.44 \leq Q \leq 67.89 \mathrm{I} / \mathrm{s}$, $0.1 \leq h / B_{c} \leq 3.8$ and $0.17 \leq r \leq 0.88$. According to Fig. 8 , for Models I, II, III and IV, respectively, $84 \%, 87 \%, 50 \%$ and $87 \%$ of the discharge errors are within $\pm 5 \%$. Similarly, for Models I, II, III and IV, respectively, 58\%, 65\%, 33\% and $66 \%$ of the discharge errors are within $\pm 2.5 \%$. Table 2 shows that proposed simple Model IV is more effective and accurate than the others for discharge estimation. The calculations show that the average discharge error of Model IV increases from $1.66 \%$ in calibration stage up to $3.95 \%$ in validation stage. Model IV with simpler form is marginally more accurate than Model II. Model III does not consider the contraction ratio $r$. This model with low prediction power does not have good accuracy. The calculations show that the average error of Model III increases from $4.92 \%$ in calibration stage up to $13.54 \%$ in validation stage. As will be shown, the contraction ratio can be neglected from the discharge equation (Eq. 10) only for a specified range of $r$. Both Model I and Model II are semi-analytical based solutions but Model II is more accurate and simpler than Model I. Model I is the most complex one. Model I has two empirical coefficients while Model II has three empirical coefficients, however, Model I is more data dependent with higher errors in validation stage. Moreover, Model I has no solution for last run of this study $\left(B_{c}=0.25 \mathrm{~m}, h=0.2559 \mathrm{~m}\right.$ and $Q=67.886 \mathrm{l} / \mathrm{s}$ ). The distribution of relative error of the proposed models compared with experimental data is plotted versus $Q$ in Fig. 9. A perusal of Fig. 9 reveals that Model IV with relatively simple form is sufficiently accurate for all practical purposes. 
Table 2 Average and maximum errors for different proposed stage-discharge models

\begin{tabular}{|c|c|c|c|c|c|c|}
\hline \multirow[t]{2}{*}{ Proposed model } & \multicolumn{2}{|c|}{$\begin{array}{l}\text { Calibration stage } \\
\text { (83 runs) }\end{array}$} & \multicolumn{2}{|c|}{$\begin{array}{l}\text { Validation stage ( } 36 \\
\text { runs) }\end{array}$} & \multicolumn{2}{|c|}{$\begin{array}{l}\text { All data sets (119 } \\
\text { runs) }\end{array}$} \\
\hline & $\begin{array}{l}\text { Average } \\
\text { error } \\
(\%)\end{array}$ & $\begin{array}{l}\text { Maxi- } \\
\text { mum } \\
\text { error }(\%)\end{array}$ & $\begin{array}{l}\text { Average } \\
\text { error } \\
(\%)\end{array}$ & $\begin{array}{l}\text { Maxi- } \\
\text { mum } \\
\text { error }(\%)\end{array}$ & $\begin{array}{l}\text { Average } \\
\text { error } \\
(\%)\end{array}$ & $\begin{array}{l}\text { Maximum } \\
\text { error (\%) }\end{array}$ \\
\hline $\begin{array}{l}\text { Model I (Eq. (2) with } a=1.085 \text { and } \beta=0.243) \text { : } \\
\qquad Q=\frac{\left(B_{c}+0.243 h\right) \sqrt{g h^{3}}}{\left(\frac{1.085}{2}+1.085 \cos \left\{\frac{1}{3} \arccos \left[1-\frac{2 r^{2}\left(1+0.243 h / B_{c}\right)^{2}}{1.0855^{3}}\right]\right\}\right)^{\frac{3}{2}}}\end{array}$ & 1.82 & 6.19 & 5.10 & 13.08 & 2.79 & 13.08 \\
\hline $\begin{array}{l}\text { Model II (Eq. (3) with } a=0.826, b=0.214 \text { and } c=0.76 \text { ): } \\
\qquad Q=\frac{0.826 B_{c} \sqrt{g h^{3}\left[1+0.214\left(h / B_{c} c^{0.76}\right]^{3}\right.}}{\left\{\frac{1}{2}+\cos \left[\frac{1}{3} \arccos \left(1-2 r^{2}\right)\right]\right\}^{\frac{3}{2}}}\end{array}$ & 1.53 & 7.62 & 4.33 & 10.93 & 2.38 & 10.93 \\
\hline Model III (Eq. (4)): $Q=0.612\left(\frac{h}{B_{c}}\right)^{1.585} \sqrt{g B_{c}^{5}}$ & 4.92 & 14.30 & 13.54 & 21.60 & 7.53 & 21.60 \\
\hline $\begin{array}{l}\text { Model IV (Eq. (12) with } a=0.407, b=-0.16, c=0.263 \text { and } d=0.407 \text { ): } \\
\qquad \begin{array}{l}0.407 r\left[1+r^{-1.16}\left(\frac{h}{B_{c}}\right)^{0.263}\right] B_{c} \sqrt{g h^{3}}\end{array}\end{array}$ & 1.66 & 5.46 & 3.95 & 8.99 & 2.35 & 8.99 \\
\hline
\end{tabular}

Fig. 8 Cumulative frequency distribution of the errors for the discharge values calculated by different models (119 runs)
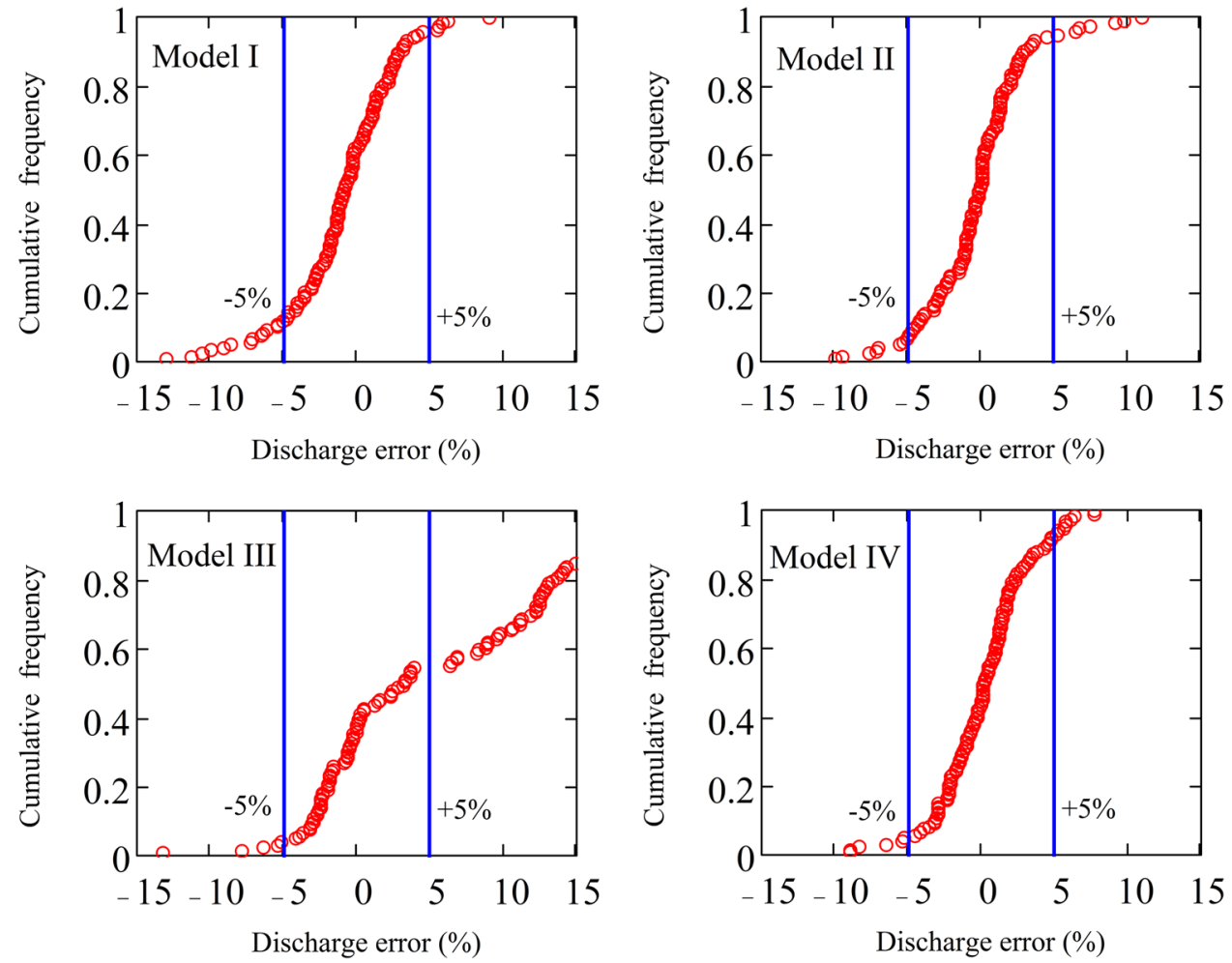
Fig. 9 Relative error distribution of the proposed models compared with experimental data
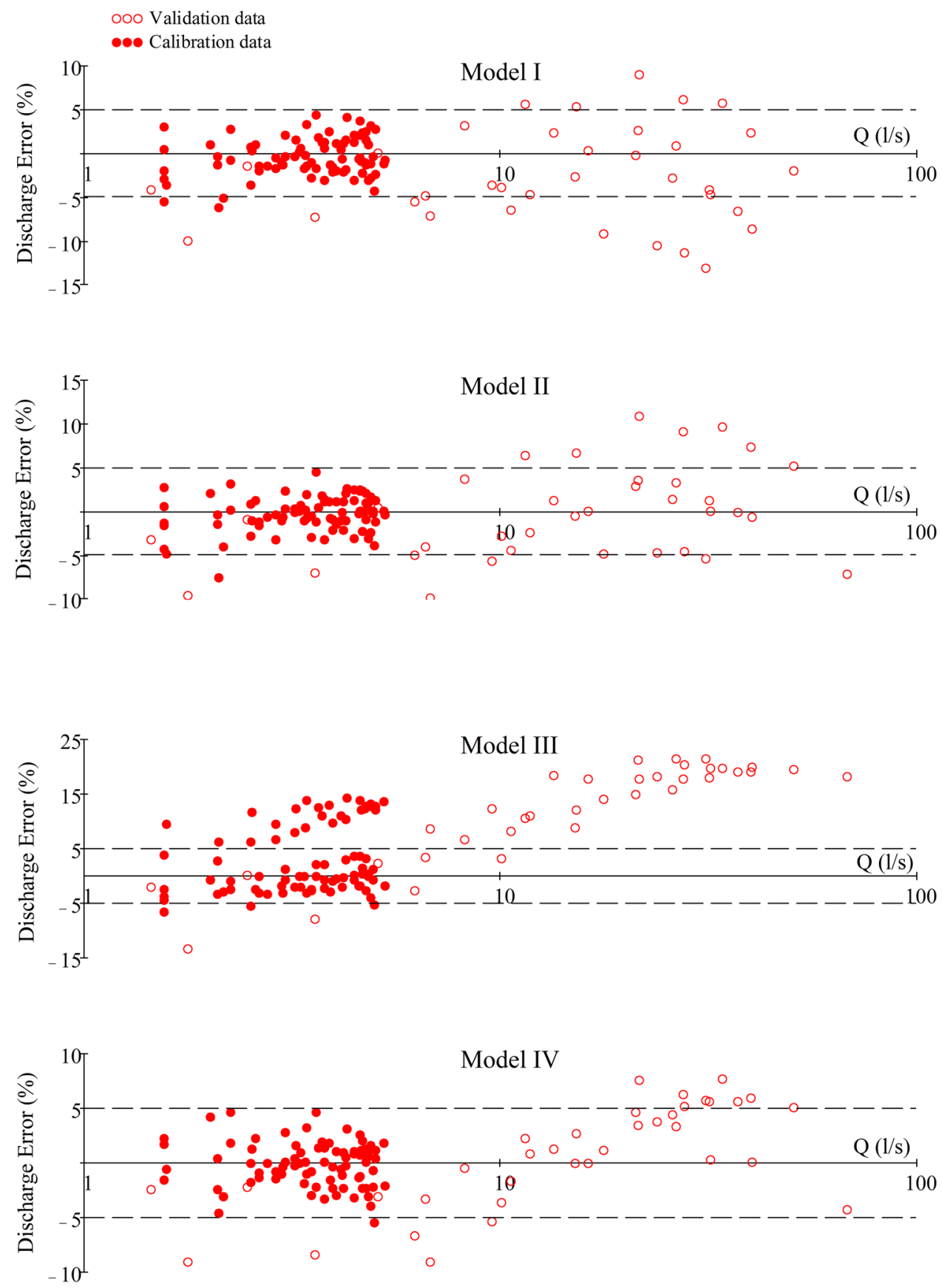

\section{Effect of contraction ratio $r=B_{C} / B$ (effect of upstream bottom width $B$ )}

In order to investigate the effect of the contraction ratio $r=B_{C} / B$ on the stage-discharge relationship, Eq. (12) should be written in an appropriate dimensionless form. Substituting $a=0.407, b=-0.16, c=0.263$ and $d=0.407$ into Eq. (12) and multiplying both sides by $\left(h / B_{c}\right)^{1.5}$ yields:
$\frac{Q}{\sqrt{g B_{c}^{5}}}=0.407 r\left(\frac{h}{B_{c}}\right)^{1.5}\left[1+r^{-1.16}\left(\frac{h}{B_{c}}\right)^{0.263}\right]$

A graphical representation of Eq. (13) is shown in Fig. 10 for different values of the contraction ratio $r$. The figure reveals that, for a given $h / B_{C^{\prime}}$ by increasing the values of $r$, the dimensionless discharge increases. Figure 10 indicates 


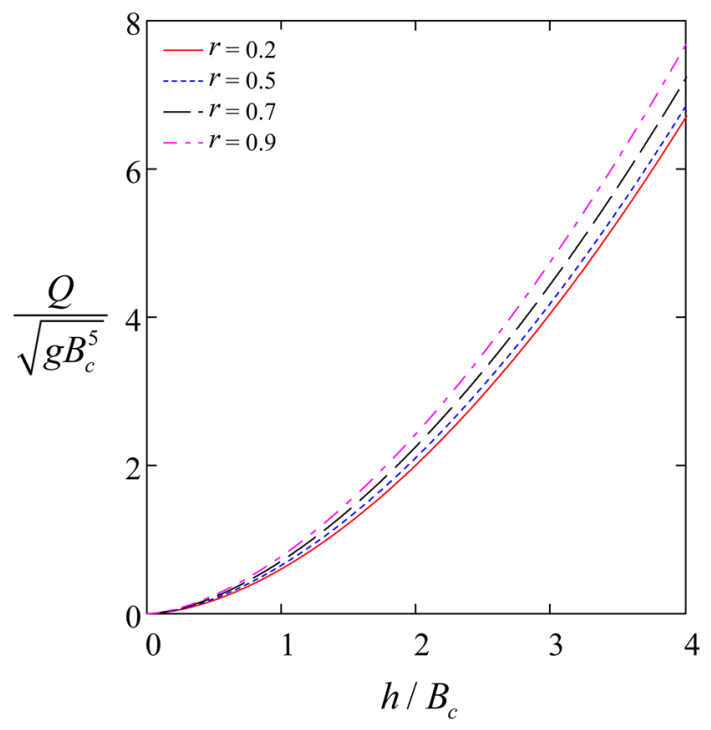

Fig. 10 Graphical representation of dimensionless discharge in terms of dimensionless depth for different values of the contraction ratio $r$

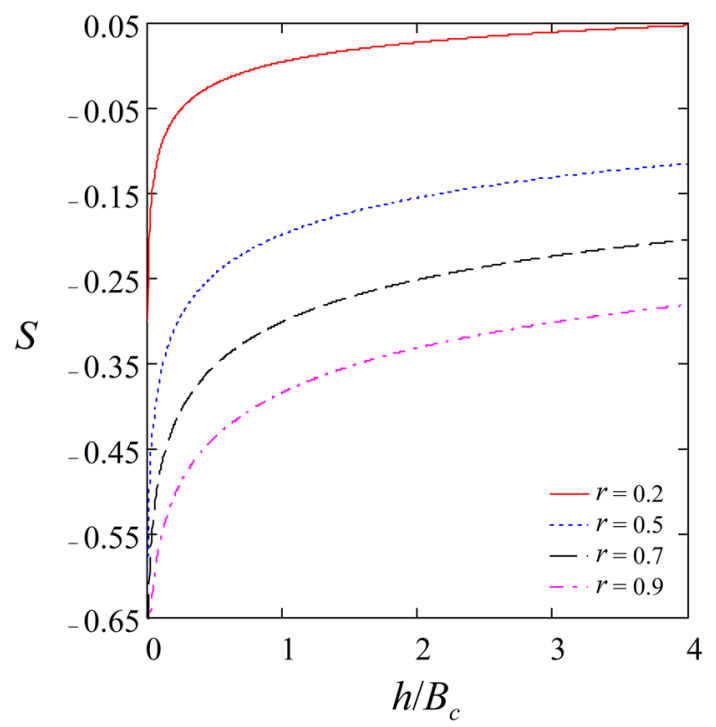

Fig. 11 Variation of the relative sensitivity $S$ against dimensionless depth for different values of the contraction ratio $r$

that the dimensionless discharge variation due to the contraction ratio variation is small for $r$ in the range of 0.2 and 0.5 . As it will be shown in the next section, this can be attributed to the upstream flow regime with low Froude number. For $r \in[0.2,0.5]$, the flow discharge may be considered quasi-independent of the contraction ratio. However, the flow discharge variation due to the contraction ratio variation is significant for the range of $r \in[0.5,0.9]$. For this range, the flow discharge cannot be considered independent of the contraction ratio $r$ (or upstream bottom width $B)$ and the stage-discharge relationship depends significantly on the contraction ratio.

The sensitivity is defined as the ratio of output variation to input variation. For the flume under study, the output and input can be respectively considered as the flow discharge, $Q$, and upstream bottom width $B$. Thus a relative sensitivity index, $S$, for the discharge, $Q$ to the upstream bottom width $B$ can be defined as follows:

$S=\frac{\frac{\partial Q}{Q}}{\frac{\partial B}{B}}=\frac{B / B_{c}}{\partial\left(B / B_{c}\right)} \frac{\partial\left(\frac{Q}{\sqrt{g B_{c}^{5}}}\right)}{\frac{Q}{\sqrt{g B_{c}^{5}}}}=\frac{-r}{\partial r} \frac{\partial\left(\frac{Q}{\sqrt{g B_{c}^{5}}}\right)}{\frac{Q}{\sqrt{g B_{c}^{5}}}}$

Using Eq. (13) one gets:

$S=-\frac{r^{1.16}-0.16\left(\frac{h}{B_{c}}\right)^{0.263}}{r^{1.16}+\left(\frac{h}{B_{c}}\right)^{0.263}}$

A graphical representation of Eq. (15) is shown in Fig. 11 for different values of the contraction ratio $r$. Based on the figure, for a given $B_{c}$ and $h / B_{c^{\prime}}$ by decreasing the values of $B$ (increasing $r$ ), the absolute value of the relative sensitivity index, $S$, increases. The figure indicates that a flume with high $r$ is more sensitive to the upstream bottom width $B$, and flumes with low $r$ are less sensitive to the upstream bottom width $B$.

\section{New stage-discharge relationship (effect of approaching channel width)}

According to Fig. 4, for the contraction ratio $r$ close to the range $[0.26,0.6]$, the stage-discharge relationship does not depend significantly on the upstream bottom width $B$, consequently, the term $r=B_{C} / B$ can be neglected from the stage-discharge relationship. Plotting the experimental pairs $\left(h / B_{c^{\prime}} Q / B_{c}\left(g h^{3}\right)^{0.5}\right)$ for the contraction ratio in the range of $[0.17,0.48]$ shows a linear relation between two variables. In this study, the following linear regression form is considered for the flow discharge without considering the upstream bottom width $B$ :

$\frac{Q}{B_{c} \sqrt{g h^{3}}}=a\left(\frac{h}{B_{c}}\right)+b$ 
The values of the regression coefficients in Eq. (16) were obtained using the experimental runs (72 runs) of Table 1 in range of $r \in[0.17,0.48]$ and by minimizing the summation of the absolute relative errors of the estimated discharges as $a=0.104$, and $b=0.506$. The stage-discharge Eq. (16) can be used for flow discharge measurement in rectangular channels regardless of their bottom width, $B$.

Equation (16) has an average discharge error of $1.85 \%$ and a maximum error of $9.5 \%$ and $93 \%$ of the measured discharge values has an estimate error less than $5 \%$. Similarly, Eq. (12) [Model IV] that is valid for all experimental data has an average error of the discharge equal to $1.66 \%$ and $87 \%$ of the measured discharge values has an estimate error less than $5 \%$.

More focus on Eq. (16) shows that this equation is in relation to the upstream Froude number, $F_{u}=Q$ / $\left[B h(g h)^{0.5}\right]$, ranges from 0.11 to $0.33(r \in[0.17,0.48])$. This indicates that $F_{u}$ probably acts as a distinguishing limit. Plotting the experimental pairs $\left(h / B_{c}, Q / B_{c}\left(g h^{3}\right)^{0.5}\right)$ for the data with the upstream Froude number in range of $0.11 \leq F_{u} \leq 0.38$ (89 runs) showed a linear relation between two variables for $r \in[0.17,0.6]$. This demonstrates that, for $F_{u} \leq 0.38$, the upstream bottom width has no significant effect on flow discharge of the flume. By minimizing the summation of the absolute relative errors of the estimated discharges ( 89 runs), the following discharge equation is obtained for the range of $0.11 \leq F_{u} \leq 0.38$ and $r \in[0.17,0.6]$ :

$\frac{Q}{B_{c} \sqrt{g h^{3}}}=0.1\left(\frac{h}{B_{c}}\right)+0.515$

Equation (17) has an average discharge error of $2.1 \%$ and a maximum error of $10.9 \%$ and $91 \%$ of the measured discharge values has an estimate error less than $5 \%$. While Eq. (16) is valid for $0.11 \leq F_{u} \leq 0.33$ and $r \in[0.17,48]$, Eq. (17) is valid for the wider ranges of $0.11 \leq F_{u} \leq 0.38$ and $r \in[0.17$, 0.6].
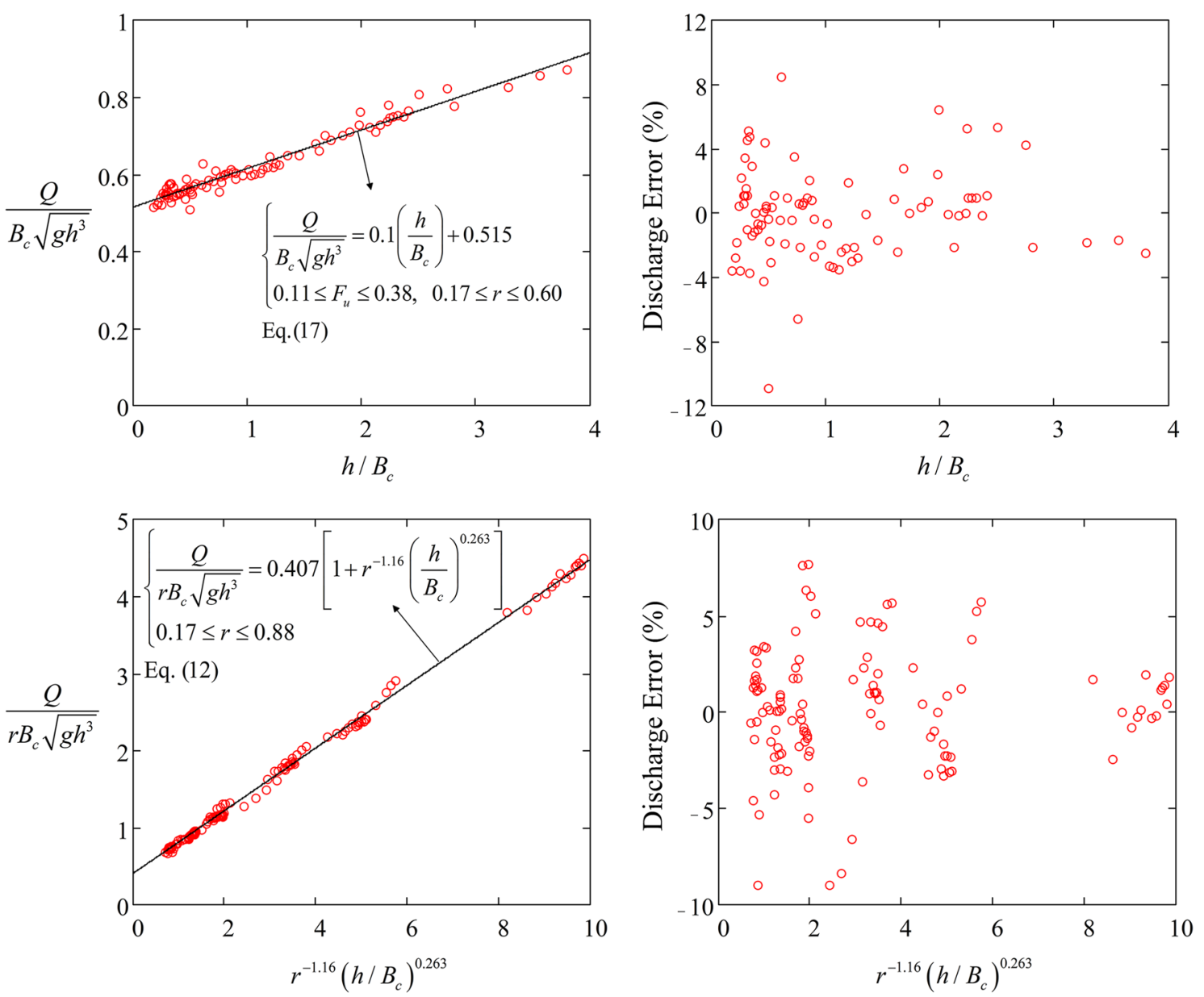

Fig. 12 Comparison of experimental discharge values (hollow circles) with computed ones using proposed Eqs. (12), and (17), along with their discharge error distributions 
A graphical representation of Eqs. (12) and (17) along with their relative errors are plotted in Fig. 12. Observation of Fig. 12 shows that the experimental discharge values (hollow circles) can be accurately estimated by Eq. (17) in ranges of $0.11 \leq F_{u} \leq 0.38$ and $r \in[0.17,0.6]$ with only two empirical coefficients. The experimental discharge values (hollow circles) can also be accurately estimated by full range stage-discharge Eq. (12) [Model IV] with three empirical coefficients and by including the contraction ratio $r$.

\section{Conclusions}

The flow through a horizontal rectangular channel with two half-pipe contractions in its walls was studied. The aim of this study was deducing a new general simple stage-discharge equation for flumes with two half-pipe contractions under the free flow regime for a wider range of discharge than that explored in the past. This equation was calibrated using the experimental runs ( 83 runs) carried out by Baiamonte and Ferro [14] and tested by some new runs (36). The experimental studies available in the literature (in the same condition) are limited to small discharges. To extend the range of previous data, new experimental runs were performed using the flow discharges in a wider range. These new experimental data were used for validation stage. For all experiments, the upstream flow regime was subcritical for any value of $r$. The effect of contraction ratio on the stage-discharge relationship was widely investigated in this study. The sensitivity analysis showed that a flume with high contraction ratio $(0.5<r)$ is more sensitive to the contraction ratio, and the flumes with low contraction ratio $(0.2<r<0.5)$ are less sensitive to the contraction ratio. The results of this study showed that the suggested Eq. (12) is a general simple stage-discharge relationship that can be used for the entire range of $r$ values $(0.17<r<0.88)$ with acceptable accuracy. In practice, it is preferable to restrict the contraction ratio to the range of $[0.2,0.5]$ to avoid high sensitivity of the discharge, $Q$ to the contraction ratio, $r$. For $0.11 \leq F_{u} \leq 0.38$ and $r \in[0.17,0.6]$, the flow discharge may be considered independent of the contraction ratio and a general linear form can be used for this situation. Compared with the available stage-discharge relationships, the proposed simple relationships [Eqs. (12) and (17)] can be used with acceptable accuracy.

To adequately capture the flow characteristics in validation data region (especially for higher discharges), the proposed model should be recalibrated using the full dataset. Recalibrating the proposed Model IV using the full dataset of Table 1 yields: $a=0.421, b=-0.125$, $c=0.305$ and $d=0.421$. In this case, Model IV has an average error of $2.20 \%$, and has a maximum error less than $9.92 \%$ for the full dataset. For the validation data (36 runs), the average error reduces from 3.95 to $3.23 \%$.

\section{Compliance with ethical standards}

Conflict of interest The authors declare that they have no conflict of interest.

\section{Appendix 1}

Using $B_{c^{\prime}} g$, and $\rho$ as repeating independent variables, the $\Pi_{1}$ has the following expression:

$\Pi_{1}=Q\left(B_{c}\right)^{a}(g)^{b}(\rho)^{c}$

where $a, b$, and $c$ are numeric constants.

Since $\Pi_{1}$ is dimensionless one gets:

$\left[Q^{-1}\right]=\left[B_{c}\right]^{a}[g]^{b}[\rho]^{c}$

where square brackets stand for the dimension of a quantity.

Inserting the dimensions of each variable yields:

$T L^{-3}=L^{a}\left(L^{b} T^{-2 b}\right)\left(M^{c} L^{-3 c}\right)$

$T L^{-3}=L^{a+b-3 c} T^{-2 b} M^{c}$

Writing the algebraic equations for the exponents that satisfy dimensional homogeneity:

$\left\{\begin{array}{l}a+b-3 c=-3 \\ -2 b=1 \\ c=0\end{array}\right.$

Solving this system of linear equations one gets:

$a=\frac{-5}{2}, b=\frac{-1}{2}, c=0$

The solution $a=-5 / 2, b=-1 / 2$ and $c=0$ establishes that $\Pi_{1}$ has the following expression: 


$$
\Pi_{1}=Q\left(B_{c}\right)^{\frac{-5}{2}}(g)^{\frac{-1}{2}}(\rho)^{0} \Rightarrow \Pi_{1}=\frac{Q}{\sqrt{g B_{c}^{5}}}
$$

Following similar procedure yields:

$$
\begin{aligned}
& \Pi_{2}=h\left(B_{c}\right)^{a}(g)^{b}(\rho)^{c} \\
& {\left[h^{-1}\right]=\left[B_{c}\right]^{a}[g]^{b}[\rho]^{c}} \\
& L^{-1}=L^{a+b-3 c} T^{-2 b} M^{c} \\
& \left\{\begin{aligned}
a+b-3 c= & -1 \\
-2 b & =0 \\
c & =0
\end{aligned}\right. \\
& \{a=-1, b=0, c=0 \\
& \Pi_{2}=h\left(B_{c}\right)^{-1}(g)^{0}(\rho)^{0} \Rightarrow \Pi_{2}=\frac{h}{B_{c}} \\
& \Pi_{3}=B\left(B_{c}\right)^{a}(g)^{b}(\rho)^{c} \\
& {\left[B^{-1}\right]=\left[B_{c}\right]^{a}[g]^{b}[\rho]^{c}} \\
& L^{-1}=L^{a+b-3 c} T^{-2 b} M^{c} \\
& \left\{\begin{aligned}
a+b-3 c= & -1 \\
-2 b & =0 \\
c & =0
\end{aligned}\right. \\
& \{a=-1, b=0, c=0 \\
& \Pi_{3}=B\left(B_{c}\right)^{-1}(g)^{0}(\rho)^{0} \Rightarrow \Pi_{3}=\frac{B}{B_{c}} \\
& \Pi_{4}=\mu\left(B_{c}\right)^{a}(g)^{b}(\rho)^{c} \\
& {\left[\mu^{-1}\right]=\left[B_{c}\right]^{a}[g]^{b}[\rho]^{c}} \\
& L T M^{-1}=L^{a+b-3 c} T^{-2 b} M^{c} \\
& \left\{\begin{array}{r}
a+b-3 c=1 \\
-2 b=1 \\
c=-1
\end{array}\right. \\
& \left\{a=\frac{-3}{2}, b=\frac{-1}{2}, c=-1\right. \\
& \Pi_{4}=\mu\left(B_{c}\right)^{\frac{-3}{2}}(g)^{\frac{-1}{2}}(\rho)^{-1} \Rightarrow \Pi_{4}=\frac{\mu}{\rho \sqrt{g B_{c}^{3}}} .
\end{aligned}
$$

\section{References}

1. Skogerboe GV, Bennet RS, Walker WR (1972) Generalized discharge relations for cutthroat flumes. J Irrig Drain Eng 98(4):569-583

2. Hager WH (1988) Mobile flume for circular channel. J Irrig Drain Eng. https://doi.org/10.1061/(ASCE)0733-9437

3. Samani Z, Magallanez H (2002) Closure to 'Simple flume for flow measurement in open channel' by Zohrab Samani and Henry Magallanez. J Irrig Drain Eng 128(2):131-132. https:// doi.org/10.1061/(ASCE)0733-9437

4. Wahl TL, Clemmens AJ, Replogle JA, Bos MG (2005) Simplified design of flumes and weirs. Irrig Drain 54(2):231-247

5. Raza A, Latif M, Nabi G (2007) Fabrication and evaluation of a portable long-throated flume. Irrig Drain 56(5):565-575

6. Carollo FG, Di Stefano C, Ferro V, Pampalone V (2016) New stage-discharge relationship for the SMBF flume. J Irrig Drain Eng 142(5):04016005. https://doi.org/10.1061/(ASCE)IR.19434774.0001005

7. Tekade SA, Vasudeo AD, Ghare AD, Ingle RN (2016) Dimensionless discharge in supercritical flow regime for different sizes of cutthroat flumes. Arab J Sci Eng 41(10):4235-4245

8. Das R, Nayek M, Das S, Dutta P, Mazumdar A (2017) Design and analysis of $0.127 \mathrm{~m} \mathrm{(5")} \mathrm{cutthroat} \mathrm{flume.} \mathrm{AIN} \mathrm{Shams} \mathrm{Eng} \mathrm{J}$ 8(3):295-303

9. Temeepattanapongsa S, Merkley GP, Barfuss SL, Smith B (2014) Generic unified rating for Cutthroat flumes. Irrig Sci 32(1):29-40

10. Samani Z, Magallanez $\mathrm{H}$ (2000) Simple flume for flow measurement in open channel. J Irrig Drain Eng. https://doi.org/10.1061/ (ASCE)0733-9437

11. Ferro V (2002) Discussion of 'Simple flume for flow measurement in open channel' by Zohrab Samani and Henry Magallanez. J Irrig Drain Eng 128(2):129-131. https://doi.org/10.1061/ (ASCE)0733-9437

12. Samani $Z$ (2017) Three simple flumes for flow measurement in open channels. J Irrig Drain Eng 143(6):04017010

13. Vatankhah AR (2017) Discussion of "new stage-discharge equation for the SMBF flume" by Francesco Giuseppe Carollo, Costanza Di Stefano, Vito Ferro, and Vincenzo Pampalone. J Irrig Drain Eng 143(8):07017011

14. Baiamonte G, Ferro V (2007) Simple flume for flow measurement in sloping open channel. J Irrig Drain Eng. https://doi. org/10.1061/(ASCE)0733-9437

15. Di Stefano C, Di Piazza GV, Ferro V (2008) Field testing of a simple flume (SMBF) for flow measurement in open channels. J Irrig Drain Eng 134(2):235-240. https://doi.org/10.1061/ (ASCE)0733-9437

16. Pritchard PJ, Fox RW, McDonald AT (2010) Introduction to fluid mechanics, 8th edn. Wiley, New York

17. Munson B, Rothmayer A, Okiishi T (2012) Fundamentals of fluid mechanics, 7th edn. Wiley, Hoboken

Publisher's Note Springer Nature remains neutral with regard to jurisdictional claims in published maps and institutional affiliations. 